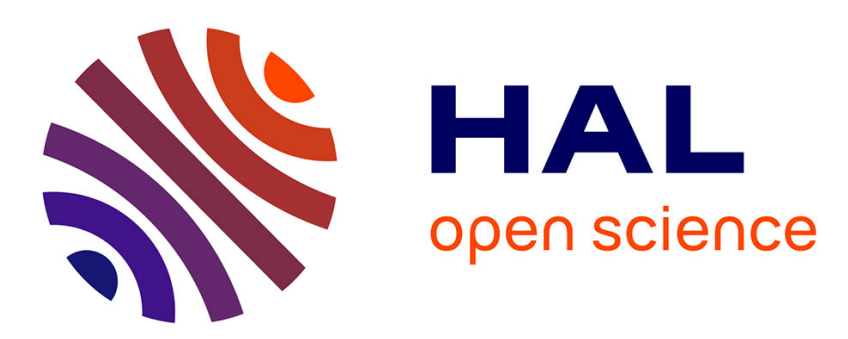

\title{
Regeneration of a thiolated and antibody functionalized GaAs (001) surface using wet chemical processes
}

\author{
Vivien Lacour, Céline Elie-Caille, Thérèse Leblois, Jan Dubowski
}

\section{To cite this version:}

Vivien Lacour, Céline Elie-Caille, Thérèse Leblois, Jan Dubowski. Regeneration of a thiolated and antibody functionalized GaAs (001) surface using wet chemical processes. Biointerphases, 2016, 11 (1), pp.019302. 10.1116/1.4942878 . hal-01914435

\section{HAL Id: hal-01914435 \\ https://hal.science/hal-01914435}

Submitted on 7 Nov 2018

HAL is a multi-disciplinary open access archive for the deposit and dissemination of scientific research documents, whether they are published or not. The documents may come from teaching and research institutions in France or abroad, or from public or private research centers.
L'archive ouverte pluridisciplinaire HAL, est destinée au dépôt et à la diffusion de documents scientifiques de niveau recherche, publiés ou non, émanant des établissements d'enseignement et de recherche français ou étrangers, des laboratoires publics ou privés. 


\title{
Regeneration of a thiolated and antibody functionalized GaAs (001) surface using wet chemical processes
}

\author{
Vivien Lacour \\ MN2S Department, FEMTO-ST Institute, Université de Franche-Comté, 15B, Av. des Montboucons, \\ 25030 Besançon, France and Laboratory for Quantum Semiconductors and Photon-based \\ BioNanotechnology, Interdisciplinary Institute for Technological Innovation (3IT), CNRS UMI-3463, \\ Université de Sherbrooke, 3000, boul. de l'Université, Sherbrooke, Québec J1K OA5, Canada
}

Céline Elie-Caille and Thérèse Leblois ${ }^{\mathrm{a})}$

MN2S Department, FEMTO-ST Institute, Université de Franche-Comté, 15B, Av. des Montboucons, 25030 Besançon, France

Jan J. Dubowski ${ }^{\text {b) }}$

Laboratory for Quantum Semiconductors and Photon-based BioNanotechnology, Interdisciplinary Institute for Technological Innovation (3IT), CNRS UMI-3463, Université de Sherbrooke, 3000, boul. de l'Université, Sherbrooke, Québec J1K 0A5, Canada

Wet chemical processes were investigated to remove alkanethiol self-assembled monolayers (SAMs) and regenerate GaAs (001) samples studied in the context of the development of reus-able devices for biosensing applications. The authors focused on 16-mercaptohexadecanoic acid (MHDA) SAMs that are commonly used to produce an interface between antibodies or others proteins and metallic or semiconductor substrates. As determined by Fourier transform infrared absorption spectroscopy, among the investigated solutions of $\mathrm{HCl}, \mathrm{H}_{2} \mathrm{O}_{2}$, a n d $\mathrm{N} \mathrm{H}_{4} \mathrm{OH}$, the high-est efficiency in removing alkanethiol SAM from GaAs was shown by $\mathrm{NH}_{4} \mathrm{OH}: \mathrm{H}_{2} \mathrm{O}_{2}$ (3:1 vol-ume ratio) diluted in $\mathrm{H}_{2} \mathrm{O}$. The authors observed that this result was related to chemical etching of GaAs that even in a weak solution of $\mathrm{NH}_{4} \mathrm{OH}: \mathrm{H}_{2} \mathrm{O}_{2}: \mathrm{H}_{2} \mathrm{O}$ (3:1:100) proceeded at a rate of $130 \mathrm{~nm} / \mathrm{min}$. The surface revealed by a 2 -min etching under these conditions allowed depositing successfully a new MHDA SAM with comparable quality and density to the initial coating. This work provides an important view on the perspective of the development of a family of cost-effective GaAs-based biosensors designed for repetitive detection of a variety of biomole-cules immobilized with dedicated antibody architectures.

\section{INTRODUCTION}

Self-assembled monolayers (SAMs) of alkanethiols have been widely investigated for biosensing applications involving surface-immobilized biomolecules or other biological entities. ${ }^{1,2}$ Typically, alkanethiol SAMs are formed either on metallic or semiconductor substrates. Alkanethiol SAMs on GaAs (001) have been investigated for many years, and they have often been discussed in the context of electronic and chemical passivation. ${ }^{3}$ The emergence of GaAs in the field of biosensors $^{4-6}$ implies an extensive characterization of GaAs-biosensing layer interfaces. In the case of immunosensors, the biological receptors (antibodies) are linked to the semiconductor surface by carboxylic acid terminated alkanethiols that could form strong amide bonds with antibodies. The ability to regenerate the biochemical interface is critical for a biosensor in order to promote low cost sensing operations. For a reproducible fabrication of the biosensor, it is essential to have techniques for the regeneration of GaAs surfaces that preserves the morphology and crystal structure of the GaAs initial surface. Numerous techniques,

\footnotetext{
a)Electronic mail: therese.leblois@femto-st.fr

b) Author to whom correspondence should be addressed; electronic mail: jan.j.dubowski@usherbrooke.ca
}

compatible with air and liquid environments, have been developed to clean and regenerate Au functionalized surface. The gas-compatible techniques include thermal desorption, ${ }^{7}$ plasma, ${ }^{8}$ ozone and UV light, ${ }^{9}$ laser-induced desorption, ${ }^{10}$ and UV-photo-oxidation (UVPO). ${ }^{11}$ Among liquid-compatible techniques, the most commonly used is electrochemical etching. ${ }^{12}$ Recently, Johnson and Mutharasan reported on an effective technique of cleaning by the UVPO process in liquid. ${ }^{13}$ However, only wetchemistry techniques allow processing without requirement of relatively sophisticated equipment. Examples include etching in $\mathrm{H}_{2} \mathrm{O}_{2}-\mathrm{H}_{2} \mathrm{SO}_{4}, \mathrm{H}_{2} \mathrm{O}_{2}-\mathrm{NH}_{4} \mathrm{OH},{ }^{14}$ or sulfochromic acid $\left(\mathrm{H}_{2} \mathrm{SO}_{4}-\mathrm{H}_{2} \mathrm{CrO}_{4}\right)^{15}$ solutions. Wet chemistry provides fast and simple regeneration of functionalized $\mathrm{Au}$ substrates, and it is attractive to provide in situ regeneration of such substrates. In contrast, despite a relatively rich literature on the fabrication of atomically clean GaAs (001) wafers, the information on regeneration of biofunctionalized GaAs surfaces is largely missing.

In this paper, we report on an investigation of a wet chemistry process designed for removal of SAMs of alkanethiols and antibodies employed for biofunctionalization of GaAs (001) surfaces. This approach addresses fabrication of surfaces suitable for refunctionalization. 


\section{EXPERIMENTAL AND METHODOLOGY}

\section{A. Materials}

Undoped (semi-insulating) double side polished GaAs (100) $\pm 0.5^{\circ}$ (AXT, Inc., Fremont, USA) wafers, $617 \mu \mathrm{m}$ thick, were used in this study. Semiconductor grade Opticlear (National Diagnostics), acetone (ACP Chemicals, Canada), anhydrous ethanol (Brampton, Canada), ammonium hydroxide (28\%, Anachemia, Canada), hydrochloric acid (35\%, Anachemia, Canada), and hydrogen peroxide (30\%, Anachemia Canada) were used as received. Degassed ethanol solution (typically $250 \mathrm{ml}$ ) was prepared by flushing with a high-purity nitrogen stream (Praxair, Canada) at 3 standard cubic feet per hour for $3 \mathrm{~h}$. 16-mercaptohexadecanoic acid (MHDA, 90\%) was purchased from Sigma Aldrich (Oakville, Canada). N-hydroxysuccinimide (NHS) and 1-ethyl-3-(3diméthylaminopropyl)carbodiimide hydrochloride (EDC) included in the Amine Coupling Kit (GE Healthcare Life Sciences) were diluted in deionized water at $0.1 \mathrm{M}$ for NHS and $0.4 \mathrm{M}$ for EDC. After solubilization, reagents were separately aliquoted in $250 \mu \mathrm{l}$ tube and stored at $-20^{\circ} \mathrm{C}$. Polyclonal antibodies against Escherichia coli bacteria were bought from Virostat, Inc. (Portland, ME), and phosphate buffered saline $10 \times$ solution (PBS) was purchased from Sigma Aldrich.

\section{B. Fourier transform infrared spectroscopy}

Infrared spectra of chemically functionalized GaAs samples were recorded in a transmission mode using a Bruker Optics Hyperion 2000 FTIR-microscope, coupled with a Bruker RockSolid interferometer, and using a wide range Globar infrared source covering spectral range between 6000 and $10 \mathrm{~cm}^{-1}$. The signal was collected by a liquid nitrogen cooled mercury cadmium telluride IR detector. An $8 \mathrm{~mm}$ diameter IR beam was focused with a $15 \times$ objective to get an approximately $0.5 \mathrm{~mm}$ in diameter spot on the sample. The spectral resolution was set to $4 \mathrm{~cm}^{-1}$, and all measurements were carried out in a nitrogen purged environment. For each case, spectra were averaged over 512 scans. Monolayer spectra were subtracted from the spectrum of a freshly etched GaAs (100) sample. MHDA SAM coated samples were characterized before and after chemical treatment, which allowed us to estimate SAM densities and the rate of SAM removal. All FTIR data were collected for three separate samples prepared nominally under the same conditions, which allowed determining average peak intensities reported in this paper.

\section{Preparation of MHDA coated samples}

Prior to SAM deposition, $4 \times 4 \mathrm{~mm}$ samples of GaAs (100) were cleaned in an ultrasonic bath sequentially with Opticlear, acetone, and ethanol for $5 \mathrm{~min}$ each. After drying, the samples were immersed in concentrated ammonium hydroxide for $2 \mathrm{~min}$ to remove native oxides. The samples were then quickly rinsed with deoxygenated anhydrous ethanol and immediately incubated in $2 \mathrm{mM}$ thiolate solutions. Alkanethiols of MHDA were dissolved in degassed anhydrous ethanol. After immersion, all samples were rinsed thoroughly with anhydrous ethanol followed by an ultrasonic cleaning for $30 \mathrm{~s}$ in ethanol to remove, as much as possible, all physically adsorbed thiols. Finally, samples were blown dry with nitrogen and immediately stored in individual Eppendorf tubes for characterization and chemical treatment. After chemical treatment, the samples were rinsed in anhydrous ethanol and again blown dry with nitrogen. All different samples used in this work were prepared and measured in duplicate.

\section{Immobilization of antibodies on MHDA coated samples}

Carboxylic acids terminal group of the SAM were used to immobilize antibodies through the carbodiimide-mediated reaction. To ensure covalent binding with antibodies, SAM coated samples were immersed for $30 \mathrm{~min}$ in mixed NHS $(0.1 \mathrm{M})$ and EDC $(0.4 \mathrm{M})$. Aliquoted reagents of EDC and NHS were thawed, and the solution was used directly after mixing both reagents (unstable over time). After activation, unreacted NHS and EDC were removed by rinsing with deionized (DI) water; this step was followed by the exposure of samples to antibodies against $E$. coli diluted in PBS $(1 \times)$ at $0.1 \mathrm{mg} / \mathrm{ml}$ with $0.05 \%$ of TWEEN20. A schematic drawing of the process is shown in Fig. 1.

\section{E. Etch rate measurement}

For etch rate measurements, $12 \times 12 \mathrm{~mm}$ GaAs (100) samples were spin coated with a $1.5-\mu \mathrm{m}$ thick layer of S1813 photoresist (MicroChem). The samples were then patterned by exposing half of their surface to UV, followed by removing photoresist with a developer reagent. Etching was investigated with $\mathrm{HCl}, \mathrm{NH}_{4} \mathrm{OH}$, and $\mathrm{H}_{2} \mathrm{O}_{2}$. In addition, three dilutions of $28 \% \mathrm{NH}_{4} \mathrm{OH}: 30 \% \mathrm{H}_{2} \mathrm{O}_{2}$ (volume ratio) in DI water at 3:1:10, 3:1:50, and 3:1:100 were used to investigate etching rates of GaAs samples. Depths of the etched samples were measured by profilometry using Dektak profilometer (Dektak 150, Veeco).

\section{F. Atomic force microscopy}

The surface morphology of the investigated samples (before and after chemical treatment) was imaged with an atomic force microscope (AFM, Digital Instrument Nanoscope III). The images were collected in ambient air and at room temperature by scanning $5 \times 5 \mu \mathrm{m}$ and 10 $\times 10 \mu \mathrm{m}$ regions of samples with the AFM operating in a tapping mode (to minimize possible damage to the sample surfaces). The AFM data collected for two freshly thiolated samples and for two rethiolated samples (after etching) were used to determine average surface roughness expressed by root mean square $\left(\sigma_{\mathrm{RMS}}\right)$ values.

\section{RESULTS AND DISCUSSION}

\section{A. Self-assembled monolayer removal}

The efficiency of the etching process was monitored by tracking the absorbance of methylene peaks. In Fig. 2, we 


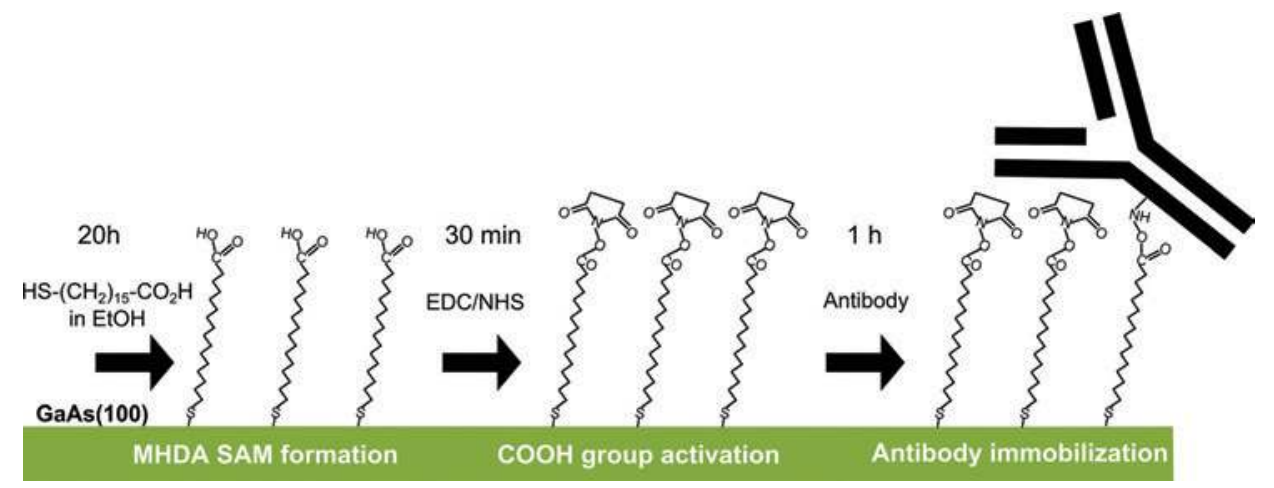

FIG. 1. Schematic idea of MHDA SAM-based functionalization of GaAs with E. coli antibodies.

compare FTIR spectra of a freshly made MHDA SAM on GaAs with those of MHDA SAMs GaAs samples exposed to $\mathrm{H}_{2} \mathrm{O}_{2}(30 \%)$ for 5,30 , and $60 \mathrm{~min}$.

The methylene absorptions at 2853 and $2922 \mathrm{~cm}^{-1}$ are assigned to, respectively, symmetric and asymmetric stretching vibrations of $\mathrm{CH}_{2}$ in alkane chains. ${ }^{16}$ It can be seen that peak intensities of these vibrations decay in proportion to the exposure time to $\mathrm{H}_{2} \mathrm{O}_{2}$. This indicates a decreasing quality of SAMs, most likely related to their decreasing density. Note that the energetic positions of methylene absorption peaks remain unchanged, which suggests that no significant SAM disordering takes place during the etching process. For samples soaked in $\mathrm{H}_{2} \mathrm{O}_{2}$, the peaks appearing at $842 \mathrm{~cm}^{-1}$ are assigned to As-O bond ${ }^{17}$ that originates from the oxides formed on the GaAs surface. These spectra exhibit decreasing $\mathrm{CH}_{2}$ and increasing As-O peaks with increasing exposure to $\mathrm{H}_{2} \mathrm{O}_{2}$, which suggests a substitution of the sulfurlinked molecules by arsenic or gallium oxide compounds. We can predict that the removal of the total amount of thiols would require a $\sim 120 \mathrm{~min}$ immersion. The removal reaction is described by the oxidation of alkanethiol compounds and the formation of sulfonates with oxygen and/or hydroxyl radicals produced by the $\mathrm{H}_{2} \mathrm{O}_{2}$ induced decomposition. $\mathrm{GaOx} /$ AsOy oxides are also formed on the surface of GaAs by the reaction with the oxidizing agent. The sulfonates are easily removed from the surface of samples rinsed with organic solvents.

Figure 3 shows intensity ratio of asymmetric stretching $\mathrm{CH}_{2}$ peaks versus immersion time in $\mathrm{HCl}, \mathrm{NH}_{4} \mathrm{OH}, \mathrm{H}_{2} \mathrm{O}_{2}$, and $\mathrm{NH}_{4} \mathrm{OH} / \mathrm{H}_{2} \mathrm{O}_{2}$ (volume ratio) based solutions. For samples immersed in acid/base etchants, a systematic decrease can be seen of the $\mathrm{CH}_{2}{ }^{\text {asy }}$ peak intensity, which is indicative of the removal or cleavage of alkanethiols from the surface.

It is possible that the etching process could be affected by islands of SAM, typically $10 \mathrm{~nm}$ in size, that are known to form during thiolation of GaAs. ${ }^{18,19}$ However, given that all the samples investigated in this paper were fabricated following a 20-h incubation, and that the coverage with these

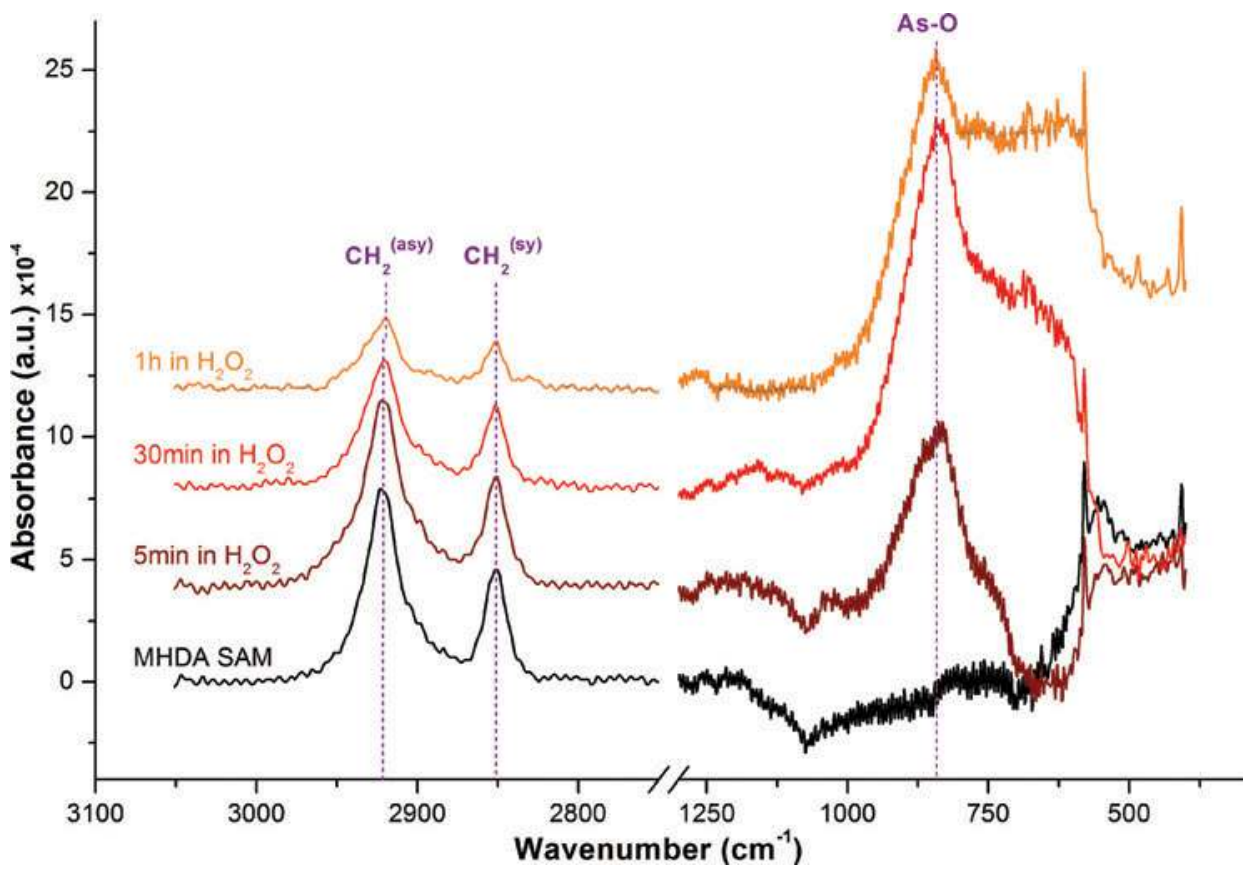

FIG. 2. Infrared spectra of MHDA SAM coated GaAs (100) samples immersed in hydrogen peroxide $\left(\mathrm{H}_{2} \mathrm{O}_{2}\right)$ for various soaking time. 


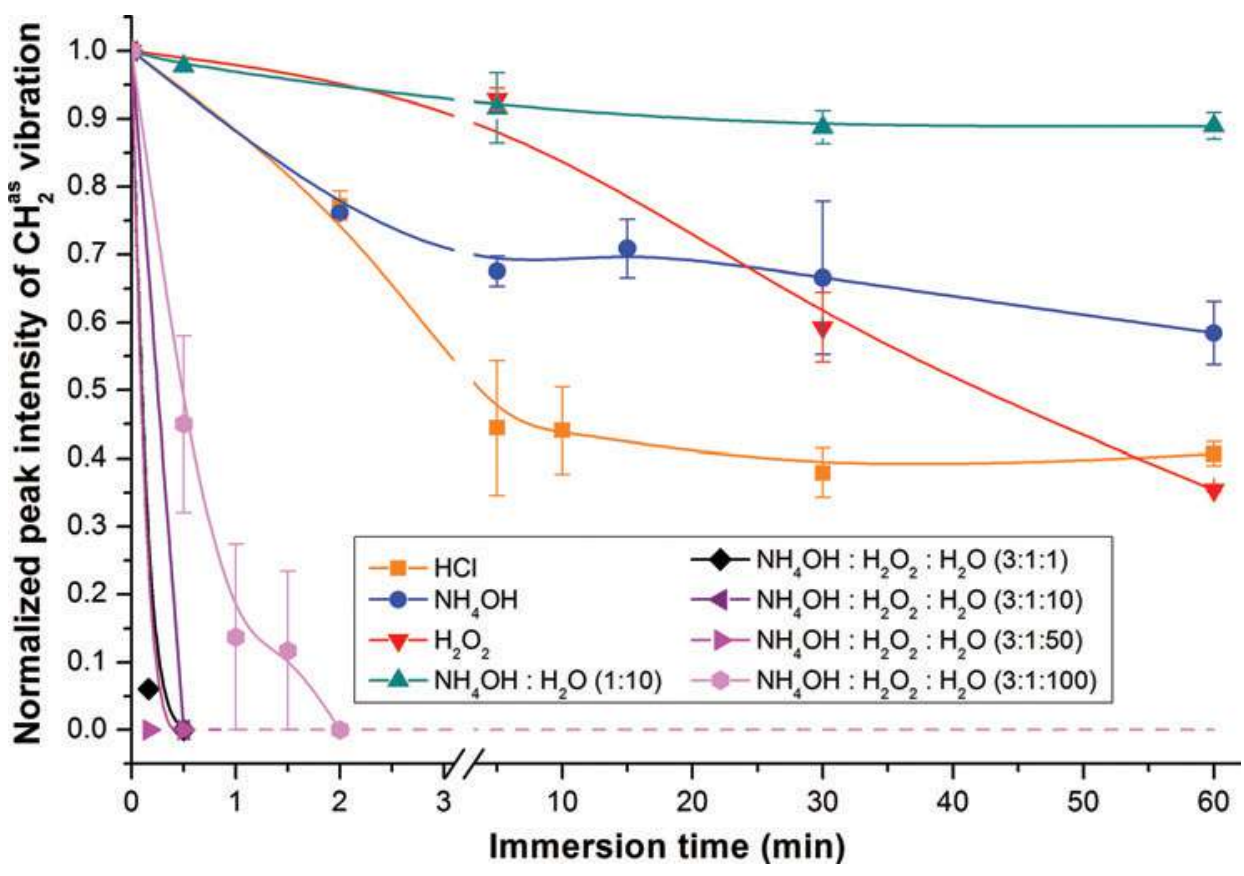

FIG. 3. SAM removal efficiency (absorbance of asymmetric $\mathrm{CH}_{2}$ peak) as a function of the immersion time in various etchants.

islands is expected to saturate within $10-15 \mathrm{~h}$ of the incubation, ${ }^{20}$ we do not expect that the etching process was affected in a measurable way by the presence of these islands. Furthermore, no macroscale lateral inhomogeneities of SAMs were observed with our FTIR data and the AFM measurements reported in Sec. III B.

As can be seen in Fig. 3, SAMs were not completely removed in $\mathrm{HCl}, \mathrm{NH}_{4} \mathrm{OH}, \mathrm{H}_{2} \mathrm{O}_{2}$, and $\mathrm{NH}_{4} \mathrm{OH}: \mathrm{H}_{2} \mathrm{O}_{2}$ solutions even after 30-min immersion. Alkanethiols SAMs have been known to provide some protection against exposure to corrosive chemicals. $^{21-23}$ As reported by Ma et al., SAMs defect sites are attacked by corrosive solution causing the removal of closely bound thiols and the corrosion of underlying substrate. ${ }^{21}$ The remaining surface is still protected by alkanethiols and could remain stable over extended time even in the presence of strong corrosive agents. It is also possible that the hydrophilic MHDA terminal group ${ }^{24}$ is cleaved relatively easily from the alkane chain that acts as a strong hydrophobic barrier. Our results of etching in $\mathrm{HCl}$, $\mathrm{NH}_{4} \mathrm{OH}$, and $\mathrm{NH}_{4} \mathrm{OH}: \mathrm{H}_{2} \mathrm{O}_{2}$ presented in Fig. 3 are consistent with the related literature reports. The exposure to $\mathrm{H}_{2} \mathrm{O}_{2}$ results in a slightly different situation. An $\mathrm{H}_{2} \mathrm{O}_{2}$ solution slowly oxidizes the surface, and after $1 \mathrm{~h}$ exposure, $35 \%$ of the initial peak intensity is reached (see also Fig. 2). It is clear that in order to remove the investigated SAMs, the application of more aggressive etching solutions is required. The mechanism of wet etching of GaAs involves oxidation of the surface to form Ga and As oxides, and dissolution of these oxides by chemical attack. Etch rates and resulting surface morphology depend on GaAs crystal orientation, composition of etching baths and their temperature. ${ }^{25}$ The etching protocol employed in this work involved oxidation with $\mathrm{H}_{2} \mathrm{O}_{2}$ and chemical etching with $\mathrm{NH}_{4} \mathrm{OH}$. Baca and
Ashby reported that a ratio $3: 1: 1$ of $\mathrm{NH}_{4} \mathrm{OH} / \mathrm{H}_{2} \mathrm{O}_{2} / \mathrm{H}_{2} \mathrm{O}$ produces smooth and crystallographic profiles of $\mathrm{GaAs}$ at room temperature. $^{26} \mathrm{NH}_{4} \mathrm{OH}-\mathrm{H}_{2} \mathrm{O}_{2}$ based solutions are widely used for surface cleaning and etching of $\mathrm{Si}$ and GaAs substrates. ${ }^{27,28}$ We used four different dilutions to investigate regeneration of the GaAs surface; three of them remove the entire coating in less than $30 \mathrm{~s}$ (dilution by 1, 10, and 50) and a 100 -fold dilution that removes thiols after 2 min of immersion. Etch rates of these solutions, evaluated by profilometry measurements, are summarized in Table I. It seems that the 3:1:100 ratio offers attractive conditions for regeneration of GaAs, without excessive removal of the substrate material.

\section{B. Efficiency of a $\mathrm{NH}_{4} \mathrm{OH}-\mathrm{H}_{2} \mathrm{O}_{2}$ based mixture in removing biofunctionalized layer}

The efficiency of wet chemical etching of antibody functionalized surfaces of $\mathrm{GaAs}$ is illustrated in Fig. 4. A C $=\mathrm{O}$ peak at $1741 \mathrm{~cm}^{-1}$ appears after activation of carboxyl terminal groups due to the presence of NHS esters ${ }^{29}$ (which contain two $\mathrm{C}=\mathrm{O}$ bonds). The presence of immobilized antibodies is illustrated by amide A, I, and II bands in the 3300, 1660, and $1520 \mathrm{~cm}^{-1}$ wavenumber regions, respectively. According to Bandekar, ${ }^{30}$ amide $\mathrm{A}$ is mainly due to the $\mathrm{N}-\mathrm{H}$ stretching vibration, amide $\mathrm{I}$ is associated with $\mathrm{C}=\mathrm{O}$ stretching vibration, and amide II is linked to $\mathrm{N}-\mathrm{H}$ bending and $\mathrm{C}-\mathrm{N}$ stretching vibration. Both amine and $\mathrm{CH}_{2}$ features disappeared

TABLE I. Etch rate of GaAs (100)—MHDA SAM samples in different solutions of $\mathrm{NH}_{4} \mathrm{OH}: \mathrm{H}_{2} \mathrm{O}_{2}: \mathrm{H}_{2} \mathrm{O}$.

\begin{tabular}{lccc}
\hline \hline $\mathrm{NH}_{4} \mathrm{OH}: \mathrm{H}_{2} \mathrm{O}_{2}: \mathrm{H}_{2} \mathrm{O}$ ratio & $3: 1: 10$ & $3: 1: 50$ & $3: 1: 100$ \\
\hline Etch rate $(\mathrm{nm} / \mathrm{min})$ & $940 \pm 46$ & $377 \pm 6$ & $127 \pm 3$ \\
\hline
\end{tabular}




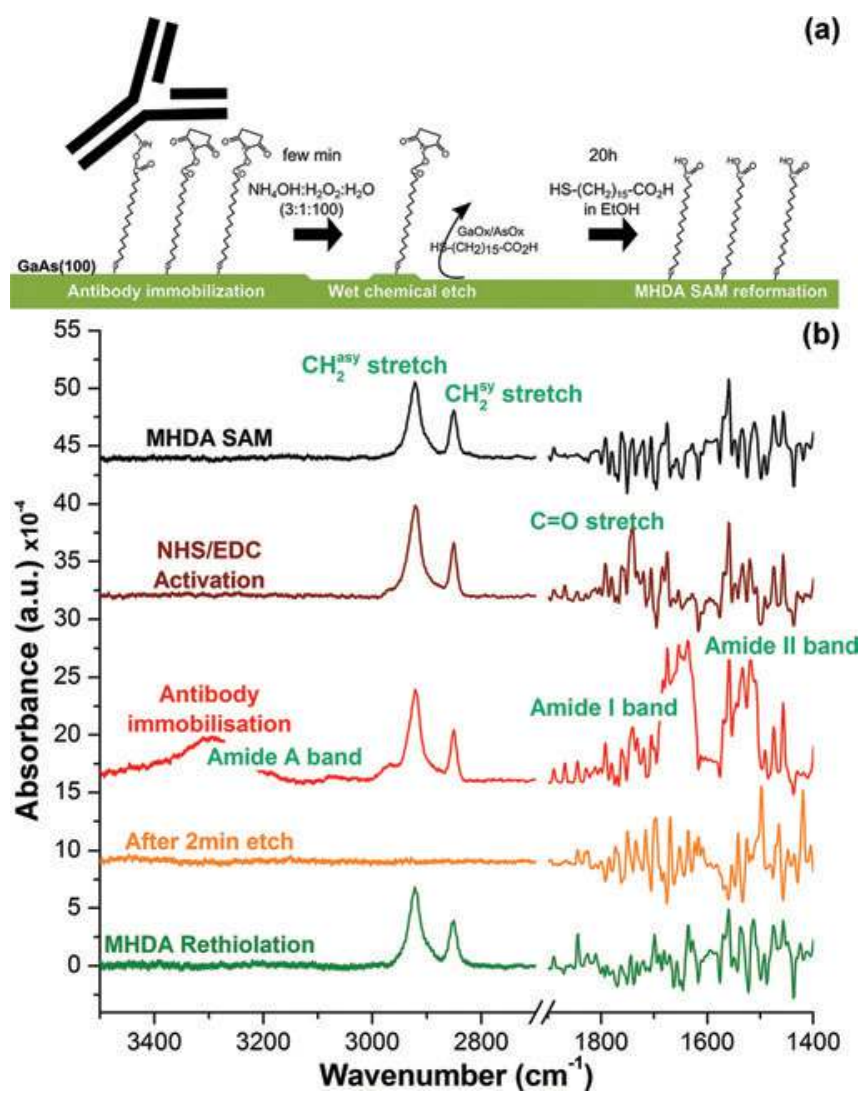

FIG. 4. Schematic idea showing the antibody functionalized architecture wet etched and regenerated by a MHDA SAM (a), FTIR spectra show $\mathrm{CH}_{2}$ stretch vibration peaks and amine-related bands for each functionalization and regeneration step (b).

entirely following a 2 min etch in the $\mathrm{NH}_{4} \mathrm{OH}: \mathrm{H}_{2} \mathrm{O}_{2}: \mathrm{H}_{2} \mathrm{O}$ (3:1:100) solution. The GaAs-MHDA superficial layer was chemically attacked by this etchant providing an efficient removal of proteins from the surface. Following this step, a new
MHDA monolayer was successfully reassembled on the GaAs surface, as characterized by the similar energy positions of $\mathrm{CH}_{2}$ features. The reassembled monolayer, characterized by $\nu_{\mathrm{CH}_{2}}^{\text {as }}$ and $\nu_{\mathrm{CH}_{2}}^{\mathrm{s}}$ at 2923.1 and $2853.0 \mathrm{~cm}^{-1}$, respectively, shows no significant shift of these peaks with respect to the original monolayer (characterized by $\nu_{\mathrm{CH}_{2}}^{\mathrm{as}}$ and $\nu_{\mathrm{CH}_{2}}^{\mathrm{s}}$ at 2922.8 and $2853.4 \mathrm{~cm}^{-1}$, respectively). However, we observed a slightly increased intensity of these peaks originating from the reassembled monolayer. For instance, the $\mathrm{CH}_{2}{ }^{\text {asy }}$ peak intensity increased from $8.8 \pm 0.6 \times 10^{-4}$ (a.u.) to $9.3 \pm 0.2 \times 10^{-4}$ (a.u.). This difference seems to be related to the increased density of SAM deposited on the GaAs substrate of a slightly increased surface roughness. Indeed, it can be seen in Fig. 5 that the GaAs (001) surface originally functionalized with MHDA SAM is characterized by the AFM $\sigma_{\text {RMS }}$ of $0.38 \mathrm{~nm}$, while that of the MHDA SAM reassembled on the 2-min etched GaAs is $2.76 \mathrm{~nm}$. The $\sigma_{\mathrm{RMS}}$ values averaged over four images collected for each of these cases were found to be $0.41 \pm 0.03$ and $2.84 \pm 0.11 \mathrm{~nm}$, respectively.

Although it is possible that the increased surface roughness of GaAs could impose the formation of an inferior quality (less organized) SAM, our FTIR diagnostics contradict this expectation. Consistent with the argument that a ridgeand-trough nanostructure helps to overcome the incommensurability of the SAM with the GaAs (001) surface $^{31}$ is that the nanoscale rough GaAs surface has also provided thiols with more freedom to reorganize, and promoted the formation of high-quality SAM, thanks to the strong thiol-thiol interaction. The attractive consequence of a slightly roughened biosensor surface provides potentially improved conditions for binding increased concentrations of proteins due to the increased surface area available for their immobilization. This effect is expected to occur if the dimensions of proteins are smaller than the width of troughs available on the rough surface. As can be seen in Fig. 5, the width of troughs is
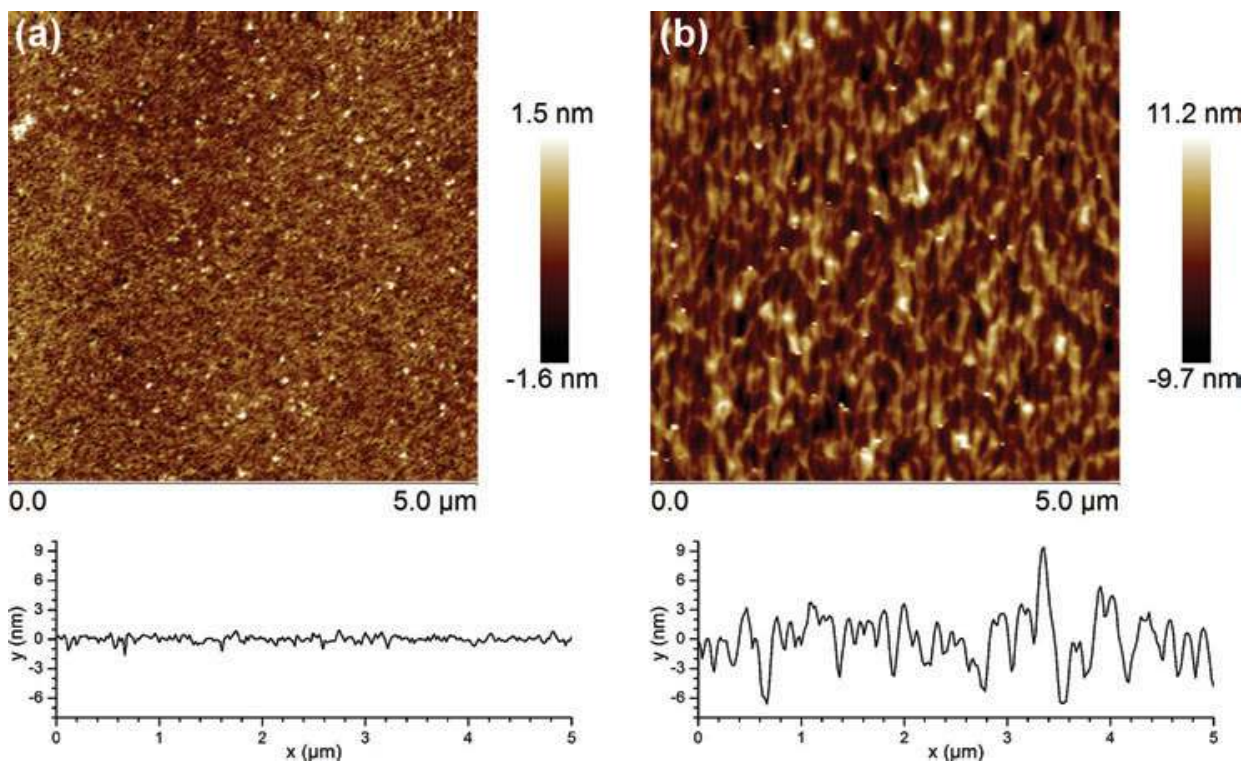

FIG. 5. Examples of AFM images of GaAs (001) surface originally functionalized with MHDA (a), and refunctionalized with MHDA after 2 min etching in 3 $\mathrm{NH}_{4} \mathrm{OH}: 1 \mathrm{H}_{2} \mathrm{O}_{2}: 100 \mathrm{H}_{2} \mathrm{O}$. 
around $134 \pm 78 \mathrm{~nm}$, which compares with the average dimensions of an antibody being $10-20 \mathrm{~nm}^{32}$ Thus, the SAM refunctionalization procedure reported in this work also has the potential to offer attractive conditions for the immobilization of enhanced density of small molecules, such as antibodies.

\section{CONCLUSION}

We have investigated various chemical treatment methods to remove organic (bio-) molecules from the surface of GaAs (001). The $\mathrm{NH}_{4} \mathrm{OH}: \mathrm{H}_{2} \mathrm{O}_{2}: \mathrm{H}_{2} \mathrm{O}$ based solutions allow achieving a relatively smooth surface of etched GaAs (001). These solutions exhibit the highest cleaning efficiency among all chemicals investigated in this work. We demonstrated that SAM and proteins (antibodies) could be removed entirely after few minutes of etching, with the GaAs (001) surface preserving its morphology to within $2.94 \mathrm{~nm}$ (RMS). Consequently, deposition of a high-quality SAM on the regenerated surface of GaAs (001) has been demonstrated in this report. This approach has the potential to offer an attractive solution where regeneration of the SAM coated GaAs (001) surface is of high importance to the cost-attractive operation of a related device.

\section{ACKNOWLEDGMENTS}

Funding for this research was provided by the region Franche-Comte (France), the Canada Research Chair in Quantum Semiconductors, the CRIBIQ-MITACS-FRQNT Project on "Development of a miniaturized device for optical reading of the QS biosensor," and the NSERC-CRD Project No. CRDPJ 452455-13. This work was also partly supported by the French RENATECH network. The authors thank Neng Liu for her assistance in collecting AFM images, and Khalid Moumanis for the help with the FTIR measurements.

${ }^{1}$ V. Duplan, Y. Miron, E. Frost, M. Grandbois, and J. J. Dubowski, J. Biomed. Opt. 14, 054042 (2009).

${ }^{2}$ L. Huang et al., Biosens. Bioelectron. 21, 483 (2005).

${ }^{3}$ G. M. Marshall, F. Bensebaa, and J. J. Dubowski, Appl. Surf. Sci. 257, 4543 (2011)

${ }^{4}$ E. Nazemi, S. Aithal, W. M. Hassen, E. H. Frost, and J. J. Dubowski, Sens. Actuators, B 207, 556 (2015).
${ }^{5}$ A. Bienaime, L. Liu, C. Elie-Caille, and T. Leblois, Eur. Phys. J.: Appl. Phys. 57, 21003 (2012).

${ }^{6}$ J. J. Dubowski, O. Voznyy, and G. M. Marshall, Appl. Surf. Sci. 256, 5714 (2010).

${ }^{7}$ M. R. Shadnam and A. Amirfazli, Chem. Commun. 38, 4869 (2005).

${ }^{8}$ K. Raiber, A. Terfort, C. Benndorf, N. Krings, and H.-H. Strehblow, Surf. Sci. 595, 56 (2005).

${ }^{9}$ Y. Zhang, R. H. Terrill, and P. W. Bohn, Chem. Mater. 11, 2191 (1999).

${ }^{10}$ M. R. Shadnam, S. E. Kirkwood, R. Fedosejevs, and A. Amirfazli, J. Phys. Chem. B 109, 11996 (2005).

${ }^{11}$ N. J. Brewer, S. Janusz, K. Critchley, S. D. Evans, and G. J. Leggett, J. Phys. Chem. B 109, 11247 (2005).

${ }^{12}$ S. Choi and J. Chae, Microfluid. Nanofluid. 7, 819 (2009).

${ }^{13}$ B. Johnson and R. Mutharasan, J. Phys. Chem. C 117, 1335 (2013).

${ }^{14}$ D. J. Kim, R. Pitchimani, D. E. Snow, and L. J. Weeks, Scanning 30, 118 (2008)

${ }^{15}$ J. Kang and P. A. Rowntree, Langmuir 23, 509 (2007).

${ }^{16}$ R. Arnold, W. Azzam, A. Terfort, and C. Wöll, Langmuir 18, 3980 (2002).

${ }^{17}$ M. Rei Vilar, J. El Beghdadi, F. Debontridder, R. Artzi, R. Naaman, A. M. Ferraria, and A. M. Botelho do Rego, Surf. Interface Anal. 37, 673 (2005).

${ }^{18}$ H. Ohno, L. A. Nagahara, W. Mizutani, J. Takagi, and H. Tokumoto, Jpn. J. Appl. Phys., Part 1 38, 180 (1999).

${ }^{19}$ C. L. McGuiness, D. Blasini, J. P. Masejewski, S. Uppili, O. M. Cabarcos, D. Smilgies, and D. L. Allara, ACS Nano 1, 30 (2007).

${ }^{20}$ C.-K. Kim, G. M. Marshall, M. Martin, M. Bisson-Viens, Z. Wasilewski, and J. J. Dubowski, J. Appl. Phys. 106, 083518 (2009).

${ }^{21}$ H. Y. Ma, C. Yang, B. S. Yin, G. Y. Li, S. H. Chen, and J. L. Luo, Appl. Surf. Sci. 218, 144 (2003).

${ }^{22}$ P. E. Laibinis and G. M. Whitesides, J. Am. Chem. Soc. 114, 9022 (1992).

${ }^{23}$ C. Kirchner, M. George, B. Stein, W. Parak, H. Gaub, and M. Seitz, "Long-term protection and functionalization of gallium arsenide surfaces in aqueous environment," in Bayreuth Polymer Symposium: International Symposium on Functional and Structural Polymeric Materials (2001), pp. 266-276.

${ }^{24}$ C. D. Bain, J. Evall, and G. M. Whitesides, J. Am. Chem. Soc. 111, 7155 (1989).

${ }^{25}$ A. Bienaime, C. Elie-Caille, and T. Leblois, J. Nanosci. Nanotechnol. 12, 6855 (2012).

${ }^{26}$ A. G. Baca and C. I. H. Ashby, Fabrication of GaAs Devices (IET, London, UK, 2005).

${ }^{27}$ J. A. Thornton, A. S. Penfold, J. L. Vossen, and W. Kern, Thin Film Processes (Academic, New York, 1978).

${ }^{28}$ C. Bryce and D. Berk, Ind. Eng. Chem. Res. 35, 4464 (1996).

${ }^{29}$ B. L. Frey and R. M. Corn, Anal. Chem. 68, 3187 (1996).

${ }^{30} \mathrm{~J}$. Bandekar, Biochim. Biophys. Acta, Protein Struct. Mol. Enzymol. 1120, 123 (1992)

${ }^{31}$ O. Voznyy and J. J. Dubowski, Langmuir 24, 13299 (2008).

${ }^{32}$ M. Reth, Nat. Immunol. 14, 765 (2013). 